\title{
Idéologie: Zur Rolle von Kategorisierungen im Wissenschaftsprozess
}

Jacques Guilhaumou

\section{(2) OpenEdition \\ 12 Journals}

Édition électronique

URL : https://journals.openedition.org/ahrf/1052

DOI : 10.4000/ahrf.1052

ISSN : 1952-403X

Éditeur :

Armand Colin, Société des études robespierristes

Édition imprimée

Date de publication : 1 mars 2001

Pagination : 134-135

ISSN : 0003-4436

Référence électronique

Jacques Guilhaumou, «Idéologie: Zur Rolle von Kategorisierungen im Wissenschaftsprozess »,

Annales historiques de la Révolution française [En ligne], 323 I janvier-mars 2001, mis en ligne le 10 avril 2006, consulté le 24 avril 2022. URL : http://journals.openedition.org/ahrf/1052 ; DOI : https://doi.org/ 10.4000/ahrf.1052

Ce document a été généré automatiquement le 24 avril 2022.

Tous droits réservés 


\title{
Idéologie: Zur Rolle von Kategorisierungen im Wissenschaftsprozess
}

\author{
Jacques Guilhaumou
}

\section{RÉFÉRENCE}

Brigitte Schlieben-Lange, Idéologie: Zur Rolle von Kategorisierungen im Wissenschaftsprozess, Schriften der Philosophisch-historischen Klasse der Heidelberger Akademie der Wissenschaften, Bans 18 (2000), Universitätverlag C.Winter, Heidelberg, 2000, 85 pages.

1 Brigitte Schlieben-Lange, récemment décédée, était l'une des meilleures spécialistes du mouvement des Idéologues tant dans l'ensemble de l'Europe qu'en France. Elle a ainsi dirigé une série d'études en ce domaine, éditées en quatre volumes (Europaïsche Sprachwissenschaft um 1800. Methodologische und historiographische Beiträge zum Umkreis des «Idéologie», Munster, 1989-1994). Par ailleurs, son précédent livre, publié en français (Idéologie, révolution et uniformité de la langue, Liège, Mardaga, 1996), fait le point sur les options linguistiques des Idéologues.

2 Le présent ouvrage met plus particulièrement l'accent sur les caractéristiques doctrinales de l'Idéologie française: un programme de recherche lié à une orientation méthodologique précise; des critères classificatoires internes qui permettent de dire qui est Idéologue et quels sont les textes qui ont un statut «idéologique»; un potentiel dynamique de catégorisations du savoir; enfin un statut linguistique spécifique de ces catégorisations cognitives. Il apparaît ainsi que la classification analytique des connaissances et l'activité scientifique de catégorisation sont indissociables chez les principaux théoriciens de l'Idéologie.

3 Plus précisément, la première partie de cet ouvrage montre comment s'associe, chez les Idéologues, à une théorie de la connaissance héritée de l'empirisme anglo-écossais, et surtout du sensualisme de Condillac une position sémiotique qui permet de fixer 
analytiquement les idées par des signes et une théorie du langage construite sur le modèle de la grammaire générale. Mais ce qui fait lien entre ces différents niveaux de la connaissance, c'est un modèle génétique de la formation des connaissances qui donne sa dynamique à l'ensemble. La seconde partie, la plus importante, aborde la notion classifiante d'Idéologie. Cette notion s'élabore d'abord dans les textes des Idéologues eux-mêmes, permettant ainsi de les désigner comme tels, qu'il s'agisse du concept métathéorique d'Idéologie chez Destutt de Tracy, de «l'idéologie physiologique» de Cabanis, de l'union, chez Maine de Biran, entre idéologie et psychologie, et enfin de la nécessité posée par Degerando d'un traité d'Idéologie, pour s'en tenir aux principaux Idéologues. Puis l'auteur aborde la dimension polémique de la désignation d'Idéologue par Napoléon Bonaparte qui vise à la confusion avec le métaphysicien, pourtant exclu d'emblée de l'Idéologie par Destutt au détriment, par exemple, de la métaphysique du moi telle qu'elle est proposée par Sieyès dans son Grand cahier métaphysique, manuscrit récemment publié par nos soins (Des Manuscrits de Sieyès, sous la responsabilité de C.Fauré, Champion, 1999). La troisième partie, beaucoup plus succincte, nous met en garde contre toute lecture réductrice des Idéologues en précisant leur capacité à catégoriser au plus large, donc à constituer un véritable dispositif phénoménologique avant la lettre. De fait, c'est à partir d'une théorie du langage, abordée dans la quatrième partie, que la typification des connaissances au sein du processus cognitif initié par les Idéologues prend tout sa dimension. Il s'agit tout autant de typifier le processus de connaissance lui-même à partir d'opérations d'identification, d'interprétation et d'implication collective, que de catégoriser les connaissances acquises sur la base de l'expérience.

En fin de compte, cet ouvrage pose les bases théoriques d'une enquête en cours sur les Idéologues et la grammaire générale dans les écoles centrales, avec la participation d'Ilona Pabst et Jochen Hafner, auteur de l'annexe qui nous donne les premiers éléments documentaires sur les écrits «idéologiques» des professeurs de grammaire générale dans l'attente d'un manuel comprenant, outre des éléments biographiques sur ces professeurs, un répertoire de tous leurs écrits. 